Military Technical College

Kobry Elkobbah,

Cairo, Egypt

April 19-21,2016

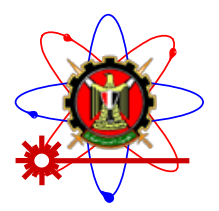

$8^{\text {th }}$ International Conference on Mathematics and Engineering Physics (ICMEP-8)

\title{
EM-7
}

\section{The Performance of Some Outranking Methods for Weapon Locating and Fire Correction Radar Selection: a Comparative Study}

By

\author{
Amr A. Abdelhalim*,Aly M. Ragab ${ }^{\dagger}$, Kamel A. Elhadad ${ }^{\ddagger}$
}

\begin{abstract}
Selection of the best weapon locating and fire correction radar is a key success factor for artillery in performing the tasks entrusted to it as an essential part of the army.The importance and complexity of the problem due to involving conflicting criteria call for analytical methods rather than intuitive decisions. This paper illustrates the application of sixdifferent outrankingmethods to the problem of selecting such radar among a finite set of candidate alternatives. The attributes (criteria) aredefined to express the performance of particular alternatives (radars) relevant for thedecision maker.The agreement between the obtained ranks are measured using Spearman's rank correlation coefficient.
\end{abstract}

Keywords:Radar selection, Outranking methods,Performance score, Spearman's rank correlation coefficient.

\section{Introduction}

No doubt, that Artillery[1] is an essential part of the army through the history, and so they should be provided with the highest and latest technological equipment to be able to perform the tasks entrusted to it in the best way. An example is the weapon locating and fire correction radar, which plays an important role in the battlefield by either locating the enemy's firing positions or correcting friendly firing.

In the area of radar selection where there are numerous different choices and various influencing criteria, one realizes that this selection can only be achieved from the use of

*Corresponding author:Military Technical College, Cairo, Egypt. Tel.: +2 01007408787 Email address: amr.abdelhalim@live.com.

${ }^{\dagger}$ Department of Operations Research, Institute of Statistical Studies and Research, Cairo University, Giza, Egypt.

${ }^{\ddagger}$ Military Technical College, Cairo, Egypt. 
Military Technical College

Kobry Elkobbah,

Cairo, Egypt

April 19-21,2016

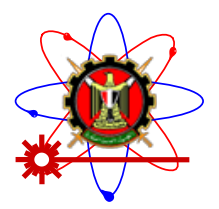

quantitative tools. Many of these attributes (criteria) are conflicting in nature and have different units, which cannot be unified and compared as they are. Thus, the decision maker experience difficulties in determining the most suitable radar alternative due to the involvement of a large number of conflicting and non-commensurate radar performancecharacteristics. The aim of this paper is to help the decision makerto choose the most appropriate weapon locating and fire correction radar based on a scientific method.

\section{Literature review}

The past researchers have successfully applied various mathematical approaches for deriving the best decisions regarding the problem of multi-attribute selection problems. JánosFülöp[2] made a report entitled “Introduction to Decision Making”. He stated the different steps for decision-making process, he focused on the multi-attribute decision making methods and finally he explained what sensitivity analysis means.MacCrimmon[3] used the max-min and max-max methods to solve a weapon system selection problem and also used the same methods to select the best pressure suit among multiple suits for Apollo mission.Milan Janic and Aura Reggiani[4] used SAW, and AHP methods to solve the problem of selecting a new hub airport where the candidate airports for establishing a new hub are the alternatives. The results have indicated that the three chosen MCDM methods have produced the same results under conditions where the same procedures for assigning weights to criteria were used.V. Athawale and S. Chakraborty[5] used 10 different methods for selecting suitable materials for:(a) A sailing boat mast, (b) a flywheel, and (c) a cryogenic storage tank. The results showed that nine methods out of 10 resulted in the same choice. Only AHP method has a comparatively poor performance.Based on actual conditions of the study area, Wang Guiqina, Qin Lib, Li Guoxuea, Chen Lijunc[6], considered economic factors, calculated criteria weights using the analytical hierarchy process (AHP), and built a hierarchy model for solving the solid waste landfill site selection problem in Beijing, China.M. Hajeeh, A. AIOthman [7] utilized AHP to select the most appropriate technology for seawater desalination. The selection process in their study was limited to seawater feed, seven factors and four commercially available desalination technologies.JM Fernandes, SP Rodrigues and Lino A. Costa [8] compared the results of using both AHP and ELECTRE I methods for prioritizing software requirements. They concluded that all stakeholders found the ELECTRE I method easier to apply. However most stakeholders prefer the results of AHP since it presents the requirements totally ordering, with numerical priorities assigned to all requirements.VP Agrawal, V Kohli, S Gupta [9] used five different MAMD methods including TOPSIS for selecting a computer aided robot. The final choice has been made based on availability of the robot, economic considerations, viability of the project, simulation of the robot's operation in the workplace, management constraints, etc. by using these considerations as attributes in the TOPSIS procedure.FajarNugraha[10] used SAW method to evaluate procurement of goods. Accordance to procurement regulations, he determined the winner in the procurement through tenders for three evaluation criteria: administrative, technical, and cost criteria. He concluded that SAWhelped the decision making in the process of evaluating alternative procurement of goods selection winner, especially, in the process of ranking based on predetermined criteria which produced more objective results.Kavishwar Roy Gaurh, Imtiyaz Khan, M. K. Ghosh 
Military Technical College

Kobry Elkobbah,

Cairo, Egypt

April 19-21,2016

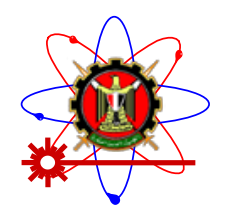

[11] used both AHP and TOPSIS methods for the selection of material handling equipment in the automobile industry. They concluded that, the criteria selected in the method is more important for selecting a material handling equipment.K. Goztepe and C.Kahraman[12] investigated the use of decision making in military processes and presented a new approach to it from MCDM point of view. They used different methods in the Course of Action (COA) development. They concluded that developing a flexible and efficient course of action to accomplish the mission in battlefield is excessively important and the key for this success is to apply a decision-making process quickly with appropriate decision-making tools.RP Mohanty[13]used AHP to select among different projects for a developing country and he found that the modelling approach used in his study has helped the organization to collate and clarify systematically various types of information. The procedure he followed has been used to replace the biased judgments of some decision makers.Ali Jahan, Faizal Mustapha and others [14] used VIKOR method for hip joint prosthesis material selection. They included five examples to illustrate and justify the suggested method.J.R. San Cristóbal[15] used VIKOR method in the selection of a renewable energy project in Spain. The results showed that the biomass plant option is the best choice.Adnan Civic and BrankoVucijak[16] applied multicriteria optimization method VIKOR to rank the options and select the best insulation of the walls on buildings. They concluded that (Styrofoam) is first-ranked alternative, which should be used for warming buildings.AHMADI, A., GUPTA, S., KARIM, R., \& KUMAR, U. [17] applied AHP, TOPSIS and VIKOR methods to select maintenance strategy for aircraft systems. The study showed that using the combined AHP, TOPSIS, and VIKOR methodologies is an applicable and effective way to identify the most effective maintenance alternative.

From the review of the past researches, it is clearly revealed that although an extensive work has already been carried out on selection problems employing different outranking methods, very little attempts have been made to compare the ranking performance of the applied methods while solving the selection problems.

This paper focuses on comparing the relative performance (results) of six most commonly used outranking methods with respect to the observed rankings of the alternative radars. Thus, in this article we are interested to answer some questions, like (a) Which is the best outranking method for achieving almost accurate rankings for the radar selection problems?, and (b) Does the best decision change for different outranking methods? We will consider different performance measures to make a comparative study on the performance of the sixoutranking methods.

\section{Outranking Methods}

Multi Criteria Decision Making (MCDM) refers to making decisions in the presence of multiple conflicting criteria. An outranking method ranks the alternatives in multi criteria selection problems and the highest ranked one is recommended as the best alternative to the decision maker.

In multi criteria selection problems, various outranking methods are presently being applied which can also be effectively used to select the most appropriate radar for army. 
Military Technical College

Kobry Elkobbah,

Cairo, Egypt

April 19-21,2016

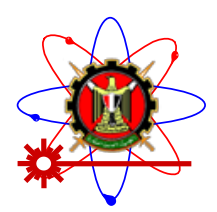

$8^{\text {th }}$ International Conference on Mathematics and Engineering Physics (ICMEP-8)

However, the vast array of available outranking methods, of varying complexity and possibly solutions, confuses the potential decision maker.

The performance of different outranking methods may be compared along varied dimensions such as perceived simplicity. In this paper, in order to compare the performance of different outranking methods while solving a radar selection problem, the following six outranking methods are considered.

a) Simple Additive Weighting (SAW) method,

b) Weighted Product Method (WPM),

c) Analytic Hierarchy Process (AHP),

d) Technique for Order Preference by Similarity to Ideal Solution (TOPSIS) method,

e) ELimination and Et Choice Translating REality(ELECTRE I) method,

f) VIKOR method.

It is also required to determine the priority weight wj of each criterion such that the sum of weights for all the criteria equals to one. These priority weights can be determined using pairwise comparisons (as in AHP methods) [18].

The computational details of these outranking methods are illustrated in the following subsections.

Simple Additive Weighting (SAW) method

Any MCDM problem can be represented by a matrix (X) consisting of $m$ alternatives and $n$ criteria.

$$
X=\left[\begin{array}{ccc}
x_{11} & \cdots & x_{1 n} \\
\vdots & \vdots & \vdots \\
x_{m 1} & \cdots & x_{m n}
\end{array}\right]
$$

where xijis the performance measure ofith alternative on jth criterion. Then, each alternative is assessed with respect to every criterion. The overall performance score (Pi) of ithalternative is calculated as follows:

$$
P_{i}=\sum_{j=1}^{N} w_{j}\left(x_{i j}\right)_{n o r m} \text { for } i=1,2, \ldots, m
$$

where (xij)norm the normalized value of xij and can be calculated as mentioned in [19]. The alternative having the highest Pi value is the best choice.

Weighted product method

This method is similar to SAW method. In SAW method.The main difference is that,instead of addition, there is multiplication in this method. The overall performance score(Pi)for ithalternative is calculated as follows:

$$
P_{i}=\prod_{j=1}^{n}\left[\left(x_{i j}\right)_{\text {norm }}\right]^{w_{j}} \text { for } i=1,2, \ldots, m
$$


Military Technical College

Kobry Elkobbah,

Cairo, Egypt

April 19-21,2016

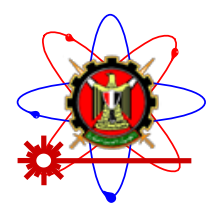

$8^{\text {th }}$ International Conference on

Mathematics and Engineering

Physics (ICMEP-8)

Here, the normalized value of ith alternative on jth criterion is raised to the power of the relative weight of the corresponding criterion. The best alternative is the one having the highest Pi value.

AHP

The AHP method as illustrated in [20] involves a general theory of measurement, which is used to derive ratio scale from both the discrete and continuous paired comparisons in multi-level hierarchical structures. The procedural steps of AHP[21] are as follows:

Step 1: Define the problem and structure the corresponding hierarchy with a goal/objective at the top level, criteria and sub-criteria at the intermediate levels and alternativesat the lowest level.

Step 2: a) Construct a set of pair-wise comparison matrices for each level in the hierarchy and make all the pair-wise comparisons using the fundamental scale of absolute numbers from 1 to 9 . An element when self-compared is assigned a value of one. Assuming that there are $\mathrm{N}$ number of criteria in a decision making problem, the pairwise comparison of ith criterion with respect to jthone yields a matrix, A1, where $a i j=1$ when $i=j$ and aij=1/aij (aij is the comparative importance of ithcriterionwith respect to jth one).

b) Find the relative normalized weight wj for each criterion by (i) calculating the geometric mean of ithrow, and (ii) normalizing the geometric mean of rows in the pairwise comparison matrix. This can be represented by the following equations:

$G M_{j}=\left[\prod_{j=1}^{n} a_{i j}\right]^{1 / N}$

$w_{j}=G M_{j} / \sum_{j=1}^{n} G M_{j}$

c) Calculate matrices A3 and A4 such that A3 = A1 x A2 and A4 = A3/A2.

where $\mathrm{A} 2=[\mathrm{w} 1, \mathrm{w} 2, \ldots, \mathrm{wN}] \mathrm{T}$.

d) Determine the maximum eigenvalue $\lambda \max$, which is the average of matrix A4.

e) Calculate the consistency index (CI) as follows:

$C I=\left(\lambda_{\max }-N\right) /(N-1)$

The smaller is the value of $\mathrm{CI}$, the smaller is the deviation from consistency.

f) Calculate the consistency ratio as $\mathrm{CR}=\mathrm{CI} / \mathrm{RI}$, where $\mathrm{RI}$ is the random index obtained by different orders of the pairwise comparison matrices. Usually, a CR of 0.1 or less is considered as acceptable which reflects an unbiased judgment of the decision maker.

Step 3: Compare the alternatives pairwise with respect to how much better they are in satisfying each of the considered criterion.

Step 4: Obtain the overall performance score for an alternative by multiplying the relative normalized weight wj of each criterion with its corresponding normalized weight value for each alternative and summing up over all the criteria for the alternative. A 
Military Technical College

Kobry Elkobbah,

Cairo, Egypt

April 19-21,2016

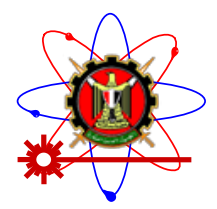

$8^{\text {th }}$ International Conference on Mathematics and Engineering Physics (ICMEP-8)

ranking of the alternatives is obtained in descending order, depending on the overall performance scores indicating the best and the worst choices for a given problem.

\section{TOPSIS}

This method is based on the concept that the chosen best alternative should have the shortest Euclidean distance from the ideal solution and is the farthest from the negative ideal solution.The main steps involved in TOPSIS method[21] are:

Step 1: We determine the goal/objective of the problem and identify the pertinent selection criteria.

Step 2: From the original decision matrix, we obtain the normalized decision matrix, (R) using thefollowing equation:

$r_{i j}=\frac{x_{i j}}{\sqrt{\sum_{i} x_{i j}^{2}}}, i=1,2, \cdots, m ; j=1,2, \cdots, k$

Step 3: We construct the weighted normalized decision matrix (V) as follows:

$v_{i j}=w_{j} r_{i j}, i=1,2, \cdots, m ; j=1,2, \cdots, k$

where wj is the relative importance weight of the jth criteria and $\Sigma$ wj=1.

Step 4: Derive the ideal (best) and the negative ideal (worst) solutions as follows:

a) For the benefit criteria:

$$
\begin{aligned}
& V^{+}=\left\{\max V_{i j} \text {, for all } i ; j=1,2, \cdots, k\right\} \\
& V^{-}=\left\{\min V_{i j} \text {, for all } i ; j=1,2, \cdots, k\right\}
\end{aligned}
$$

b) For the cost criteria:

$$
\begin{aligned}
& V^{+}=\left\{\min V_{i j}, \text { for all } i ; j=1,2, \cdots, k\right\} \\
& V^{-}=\left\{\max V_{i j}, \text { for all } i ; j=1,2, \cdots, k\right\}
\end{aligned}
$$

Step 5: Calculate the separation measures of each alternative from the ideal and the negative ideal solutions using the following equations:

$$
\begin{aligned}
& S_{i}^{+}=\sqrt{\sum_{j}\left(V_{i j}-V_{j}^{+}\right)^{2}}, i=1,2, \cdots, m \\
& S_{i}^{-}=\sqrt{\sum_{j}\left(V_{i j}-V_{j}^{-}\right)^{2}}, i=1,2, \cdots, m
\end{aligned}
$$

Step 6: The relative closeness of an alternative to the ideal solution can be expressed as below:

$$
C_{i}=S_{i}^{-} /\left(S_{i}^{+}+S_{i}^{-}\right), \quad i=1,2, \cdots, m
$$

Step 7: Based on the relative closeness measures, the alternatives are ranked in descending order, indicating the best and the worst choices.

\section{ELECRE I}


Military Technical College

Kobry Elkobbah,

Cairo, Egypt

April 19-21,2016

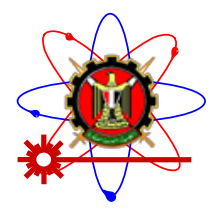

$8^{\text {th }}$ International Conference on Mathematics and Engineering Physics (ICMEP-8)

The ELECTRE method[22] is based on multi-attribute utility theory with the intention to improve efficiency without affecting the outcome while considering less information. Its procedure sequentially reduces the number of alternatives the decision maker is faced within a set of non-dominated alternatives. The aim of this outranking method is to find all alternatives that dominate other alternatives while they cannot be dominated by any other alternative.

In ELECTRE method[21], every pair of the alternatives Ai and Ak is assigned a concordance index, $\mathrm{c}(\mathrm{i}, \mathrm{k})$ which can be expressed as below:

$$
c(i, k)=\sum_{g_{j}(i)>g_{j}(k)} w_{j} \quad \mathrm{i}, \mathrm{k}=1, \ldots \mathrm{m}, \mathrm{i} \neq \mathrm{k}
$$

where gj(i) and gj(k) are the normalized measures of performance of ith and kth alternative respectively with respect to jth criterion. Thus, for an ordered pair of alternatives (Ai,Ak), the concordance index, $c(\mathrm{i}, \mathrm{k})$ is the sum of all the weights for those criteria where the performance score of $\mathrm{Ai}$ is at least as that of Ak. A discordance index, $\mathrm{d}(\mathrm{i}, \mathrm{k})$ is also calculated as given below:

$$
d(i, k)=\left\{\begin{array}{cl}
0 & \text { if } g_{j}(i)>g_{j}(k), j=1,2, \ldots, n \\
\frac{\max _{g_{j}(k)>g_{j}(i)}\left(g_{j}(i)-g_{j}(k)\right)}{\max _{j=1,2, \ldots, n}\left(g_{j}(k)-g_{j}(i)\right)} & \text { otherwise } \quad i, k=1, \ldots, m, i \neq k
\end{array}\right\}
$$

Once these two indices are determined, an outranking relation can be defined as:

$$
A_{i} S A_{k} \text { if and only if } c(i, k) \geq \bar{c} \text { and } d(i, k) \leq \bar{d}
$$

where $\bar{c}$ and $\bar{d}$ are the threshold values as set by the decision maker. For an outranking relation to bejudged as true, both the concordance and discordance indices should not violate their correspondingthreshold values. The steps for ELECTRE method[21] are:

Step 1: Obtain the normalized values of all the criteria.

Step 2: Construct the outranking relations by following the concordance and discordance definitions, and develop a graph representing the dominance relations among the alternatives. In this graph, ifalternative Ai outranks alternative Ak, then a directed arc exists from Ai to Ak.

Step 3: Obtain a minimum dominating subset by using the minimum concordance and maximumdiscordance indices.

Step 4: If the subset has a single element or is small enough to apply value judgment, select the finaldecision. Otherwise, steps (2)-(4) are repeated until a single element or small subset exists.

\section{VIKOR}

The VIKOR (the Serbian name is 'VIseKriterijumskaOptimizacijakompromisnoResenje') which means (multi-criteria optimization and compromise solution) method [23], [24] is developed to solve MCDM problems with conflicting and non-commensurate criteria. Assuming that compromise can be acceptable for conflict resolution, when the decision maker wants a feasible solution that is the closest to the ideal solution and the alternatives can be 
Military Technical College

Kobry Elkobbah,

Cairo, Egypt

April 19-21,2016

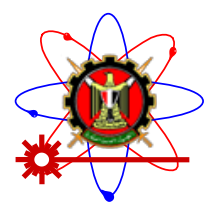

$8^{\text {th }}$ International Conference on

Mathematics and Engineering

Physics (ICMEP-8)

evaluated according to all the established criteria.The procedural steps forVIKOR method [5]are as follows:

Step 1: Identify the major selection criteria and shortlist the alternatives.

Step 2: Calculate the normalized matrix as follows:

$$
r_{i j}=\frac{x_{i j}}{\sqrt{\sum_{i} x_{i j}^{2}}}, i=1,2, \cdots, m ; j=1,2, \cdots, n
$$

Step 3: a) From the normalized decision matrix, determine the best, (rij)max and the worst, (rij)minvalues of all thecriteria.

b) Calculate Ei(the distance of the alternative to ideal solution) and Fi(the distance of the alternative to negative ideal solution)values.

$$
\begin{aligned}
& E_{i}=\sum_{j=1}^{n}\left(w_{j}\left[\left(r_{i j}\right)_{\max }-x_{i j}\right] /\left[\left(r_{i j}\right)_{\max }-\left(r_{i j}\right)_{\min }\right]\right) i=1, \ldots, m \\
& F_{i}=\max ^{m} \text { of }\left\{\left(w_{j}\left[\left(r_{i j}\right)_{\max }-r_{i j}\right] /\left[\left(r_{i j}\right)_{\max }-\left(r_{i j}\right)_{\min }\right]\right)\right\} \quad j=1, \ldots, n
\end{aligned}
$$

For non-beneficial criteria, equation (17) can be rewritten as:

$$
E_{i}=\sum_{j=1}^{n}\left(w_{j}\left[r_{i j}-\left(r_{i j}\right)_{\min }\right] /\left[\left(r_{i j}\right)_{\max }-\left(r_{i j}\right)_{\min }\right]\right) \quad i=1, \ldots, m
$$

c) Calculate Pi(relative closeness value):

$$
P_{i}=v\left(\frac{\left(E_{i}-E_{i-\min }\right)}{\left(E_{i-\max }-E_{i-\min }\right)}\right)+(1-v)\left(\frac{\left(F_{i}-F_{i-\text { min }}\right)}{\left(F_{i-\max }-F_{i-\min }\right)}\right)
$$

where Ei-max and Ei-min are the maximum and minimum values of Ei respectively, and Fi-max and Fi-minare the maximum and minimum values of Fi respectively. The value of $v$ lies in the range of 0 to 1 . Normally, its value is takenas 0.5 i.e. compromise attitude of evaluation experts.

d) Arrange the alternatives in ascending order, according to Pi values. The best alternative is the onehaving the minimum Pi value.

\section{Case study}

Our problem deals with the selection of the most appropriate weapon locating and fire correction radar for artillery. Performance of such radar is often specified using different attributes.The most critical attributes affecting the selection of weapon locating and fire correction radar relevant to the decision maker can be summarized as follows:

Max range for mortar (RM),Max range for artillery (RA), Max range for MLRS (MLRS), Max range for tactical missiles (RTM), Azimuth coverage angle(ACA), Elevation coverage angle (ECA), Max storage capacity of targets (MSC), No. of simultaneously tracked targets (NST), Mean time between failures (MTBF), Continuous operating time (COT), Crew, Setup time (ST), and Packing time (PT). 
Military Technical College

Kobry Elkobbah,

Cairo, Egypt

April 19-21,2016

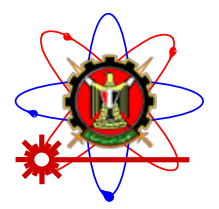

The indicated ranges represent a measure of the radar's ability to detect the different kinds of projectiles, while theindicated angles represent a measure of the radar's ability to detect the projectiles in a certain sector.Max storage capacity of targets represents the maximum number of targets about which the system can store data and No. of simultaneous tracked targetsrepresents the maximum number of targets that the radar can deal with simultaneously. Continuous operating time is a measure of the period that the radar can operate without shutdown. Crew is the minimum number of operators required to operate the radar. Setup time is the time required by the crew to start up the radar while packing time is the time required by the crew to hold fire and get the radar ready to move/evacuate.

All of the attributes are benefit criteria(where higher values are desirable), except Crew, ST, and PT, which are cost criteria (where lower values are desirable). The decision maker used pairwise comparison method developed by Saaty[25]to estimate the criteria weights as shown in table 1 .

Thus, our problem consists of 13 criteria and 4 alternatives. Table 2 demonstrates the relative performance measures of each alternative corresponding to the different criteria (decision matrix).

Table 1. The criteria weights

\begin{tabular}{|c|c|}
\hline Criteria & Weight \\
\hline Max range for tactical missiles $(\mathrm{km})$ & 0.176 \\
\hline Max range for MLRS $(\mathrm{km})$ & 0.160 \\
\hline Max range for artillery $(\mathrm{km})$ & 0.131 \\
\hline Max range for mortar $(\mathrm{km})$ & 0.118 \\
\hline Elevation coverage angle $\left(^{\circ}\right)$ & 0.099 \\
\hline Azimuth coverage angle ${ }^{\circ}$ ) & 0.082 \\
\hline No. of simultaneous tracked targets (trajectory/min) & 0.052 \\
\hline Continuous operating time (hour) & 0.049 \\
\hline MTBF (hour) & 0.046 \\
\hline Max storage capacity of targets (target) & 0.037 \\
\hline Crew & 0.019 \\
\hline Setup time (min) & 0.016 \\
\hline Packing time (min) & 0.015 \\
\hline
\end{tabular}

Table 2. Quantitative data for radar selection (decision matrix)

\begin{tabular}{|c|c|c|c|c|c|c|c|c|c|c|c|c|c||}
\hline & RM & RA & MLRS & RTM & ACA & ECA & MSC & NST & MTBF & COT & Crew & ST & PT \\
\hline SLC-2 & 15 & 30 & 40 & 55 & 90 & 95 & 100 & 8 & 150 & 20 & 3 & 7 & 7 \\
\hline $\begin{array}{c}\text { Radar } \\
\text { Complex }\end{array}$ & 25 & 30 & 40 & 80 & 60 & 32 & 64 & 12 & 220 & 20 & 3 & 5 & 3 \\
\hline RA2 radar & 30 & 50 & 80 & 150 & 90 & 95 & 100 & 8 & 200 & 12 & 4 & 5 & 3 \\
\hline WLR radar & 20 & 30 & 30 & 40 & 90 & 80 & 90 & 7 & 180 & 18 & 3 & 5 & 3 \\
\hline \hline
\end{tabular}


Military Technical College

Kobry Elkobbah,

Cairo, Egypt

April 19-21,2016

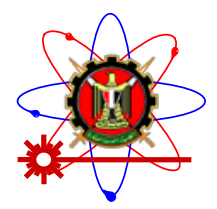

$8^{\text {th }}$ International Conference on Mathematics and Engineering Physics (ICMEP-8)

RM: Max range for mortar;RA: Max range for artillery;MLRS: Max range for MLRS; RTM: Max range for tactical missiles;ACA: Azimuth coverage angle;ECA: Elevation coverage angle;MSC: Max storage capacity of targets;NST: No. of simultaneously tracked targets;MTBF: Mean time between failures;COT: Continuous operating time;Crew, ST: Setup time;PT: Packing time.

\section{Selection Using Simple Additive Weighting Method}

In this method, the performance scores of all the radar alternatives are computed using equation (2) and are shown in table 3. Based on the descending order of the performance scorevalues, the alternatives are arranged as 3-2-1-4. This reveals that RA2 radar is the best choice.

Table 3. Performance scores using SAW method

\begin{tabular}{ccccc}
\hline \hline Radar & SLC-2 & Radar Complex & Ra2 radar & WLR radar \\
\hline Pi & 0.70849 & 0.74163 & 0.95413 & 0.666 \\
\hline \hline
\end{tabular}

\section{Selection Using Weighted Product Method}

Using equation (3), the performance scores of all the radar alternatives are calculated, as shown in table 4 . When sorted in descending order according to their performance scores, the ranking of the alternatives is obtained as 3-2-1-4, which reveals that RA2 radar is the best choice.

Table 4. Performance scores using WPM

\begin{tabular}{ccccc}
\hline \hline Radar & SLC-2 & Radar Complex & Ra2 radar & WLR radar \\
\hline Pi & 0.68225 & 0.6999 & 0.94557 & 0.63317 \\
\hline \hline
\end{tabular}

\section{Selection Using AHP}

Primarily, all the alternative radars are pairwise compared with respect to all the selection criteria using Saaty's 1-9 absolute scale of measurement[20]. Table 5 shows such a pairwise comparison matrix when all the considered alternatives are pairwise compared with respect to max range for mortar criterion.

Table 5. Pairwise comparison matrix of the alternatives with respect to max range for mortar criterion

\begin{tabular}{cccccc}
\hline \hline & SLC-2 & Radar Complex & RA2 radar & WLR radar & PW \\
\hline SLC-2 & 1 & 3 & 4 & $1 / 3$ & 0.230 \\
\hline Radar Complex & $1 / 3$ & 1 & $1 / 2$ & $1 / 6$ & 0.084 \\
\hline RA2 radar & $1 / 4$ & 2 & 1 & $1 / 4$ & 0.120 \\
\hline WLR radar & 3 & 6 & 4 & 1 & 0.566 \\
\hline \hline
\end{tabular}

The last column of this table gives the priority weights (PW) as calculated using the steps shown in sub-section (3.3). Likewise, another 12 sets of priority weights are also obtained when the alternative radars are pairwise compared with respect to the remaining 12 
Military Technical College

Kobry Elkobbah,

Cairo, Egypt

April 19-21,2016

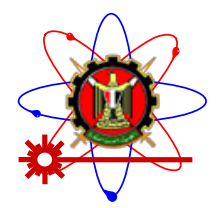

$8^{\text {th }}$ International Conference on Mathematics and Engineering Physics (ICMEP-8)

criteria. Now, using Saaty's 1-9 absolute scale of measurement, table 6 shows a pairwise comparison matrix among all the considered criteria.

Table 6. Pairwise comparison matrix among criteria.

\begin{tabular}{|c|c|c|c|c|c|c|c|c|c|c|c|c|c|}
\hline & $\mathrm{RM}$ & RA & MLRS & RTM & ACA & ECA & MSC & NST & МТВF & COT & Crew & $\mathrm{ST}$ & PT \\
\hline $\mathrm{RM}$ & 1 & 1 & $1 / 2$ & $1 / 2$ & 2 & 2 & 4 & 3 & 3 & 3 & 7 & 8 & 9 \\
\hline RA & 1 & 1 & 1 & $1 / 2$ & 2 & 2 & 4 & 3 & 3 & 3 & 7 & 8 & 9 \\
\hline MLRS & 2 & 1 & 1 & 1 & 2 & 2 & 4 & 3 & 3 & 3 & 7 & 8 & 9 \\
\hline RTM & 2 & 2 & 1 & 1 & 2 & 2 & 4 & 3 & 3 & 3 & 7 & 8 & 9 \\
\hline ACA & $1 / 2$ & $1 / 2$ & $1 / 2$ & $1 / 2$ & 1 & $1 / 3$ & 2 & 2 & 5 & 5 & 5 & 6 & 6 \\
\hline ECA & $1 / 2$ & $1 / 2$ & $1 / 2$ & $1 / 2$ & 3 & 1 & 2 & 2 & 5 & 5 & 5 & 6 & 6 \\
\hline MSC & $1 / 4$ & $1 / 4$ & $1 / 4$ & $1 / 4$ & $1 / 2$ & $1 / 2$ & 1 & $1 / 2$ & $1 / 3$ & $1 / 2$ & 6 & 3 & 5 \\
\hline NST & $1 / 3$ & $1 / 3$ & $1 / 3$ & $1 / 3$ & $1 / 2$ & $1 / 2$ & 2 & 1 & $1 / 2$ & 3 & 5 & 4 & 5 \\
\hline МТВF & $1 / 3$ & $1 / 3$ & $1 / 3$ & $1 / 3$ & $1 / 5$ & $1 / 5$ & 3 & 2 & 1 & $1 / 5$ & 5 & 4 & 2 \\
\hline COT & $1 / 3$ & $1 / 3$ & $1 / 3$ & $1 / 3$ & $1 / 5$ & $1 / 5$ & 2 & $1 / 3$ & 5 & 1 & 6 & 4 & 5 \\
\hline Crew & $1 / 7$ & $1 / 7$ & $1 / 7$ & $1 / 7$ & $1 / 5$ & $1 / 5$ & $1 / 6$ & $1 / 5$ & $1 / 5$ & $1 / 6$ & 1 & 4 & 4 \\
\hline ST & $1 / 8$ & $1 / 8$ & $1 / 8$ & $1 / 8$ & $1 / 6$ & $1 / 6$ & $1 / 3$ & $1 / 4$ & $1 / 4$ & $1 / 4$ & $1 / 4$ & 1 & 2 \\
\hline $\mathrm{PT}$ & $1 / 9$ & $1 / 9$ & $1 / 9$ & $1 / 9$ & $1 / 6$ & $1 / 6$ & $1 / 5$ & $1 / 5$ & $1 / 2$ & $1 / 5$ & $1 / 4$ & $1 / 2$ & 1 \\
\hline
\end{tabular}

RM: Max range for mortar;RA: Max range for artillery; MLRS: Max range for MLRS; RTM: Max range for tactical missiles;ACA: Azimuth coverage angle;ECA: Elevation coverage angle;MSC: Max storage capacity of targets;NST: No. of simultaneously tracked targets;MTBF: Mean time between failures; COT: Continuous operating time; Crew, ST: Setup time;PT: Packing time.

These normalized priority weights of the alternative radars with respect to different criteria are arranged in a matrix and multiplied by the criteria priority weights vector are to yield the performance scores for the alternative radars. The detailed calculations are given below. The detailed calculations are given below: 
Military Technical College

Kobry Elkobbah,

Cairo, Egypt

April 19-21,2016

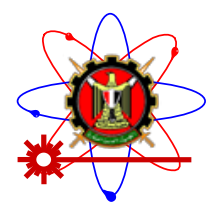

$8^{\text {th }}$ International Conference on Mathematics and Engineering Physics (ICMEP-8)

$\left[\begin{array}{lllllllllllll}0.230 & 0.132 & 0.392 & 0.550 & 0.291 & 0.392 & 0.151 & 0.190 & 0.080 & 0.382 & 0.177 & 0.063 & 0.063 \\ 0.084 & 0.160 & 0.347 & 0.277 & 0.084 & 0.057 & 0.201 & 0.514 & 0.342 & 0.382 & 0.177 & 0.313 & 0.313 \\ 0.120 & 0.264 & 0.172 & 0.107 & 0.312 & 0.392 & 0.281 & 0.190 & 0.302 & 0.130 & 0.406 & 0.313 & 0.313 \\ 0.566 & 0.444 & 0.089 & 0.066 & 0.312 & 0.160 & 0.367 & 0.106 & 0.277 & 0.105 & 0.240 & 0.313 & 0.313\end{array}\right] \times\left[\begin{array}{l}0.118 \\ 0.131 \\ 0.160 \\ 0.176 \\ 0.082 \\ 0.099 \\ 0.037 \\ 0.052 \\ 0.046 \\ 0.049 \\ 0.019 \\ 0.016 \\ 0.015\end{array}\right]=\left[\begin{array}{c}0.3098 \\ 0.2292 \\ 0.2174 \\ 0.2436\end{array}\right]$

After arranging these scores in descending order, the ranking of the radarsobtained is: 1-3-4-2.This reveals that SLC-2 is the most desirable radar for our problem.

\section{Selection Using TOPSIS}

In this method, after obtaining the normalized decision matrix using equation (7), the corresponding weighted normalized decision matrix is derived, applying equation (8). The weighted normalized decision matrix is shown in table 7.

Table 7. Weighted normalized matrix

\begin{tabular}{|c|c|c|c|c|c|c|c|c|c|c|c|c|c|}
\hline & & & & & & & CRITERI & & & & & & \\
\hline & 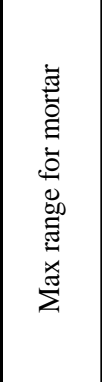 & 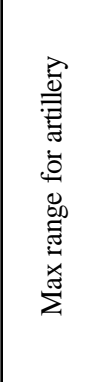 & 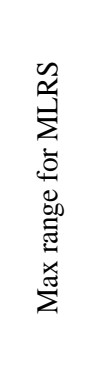 & 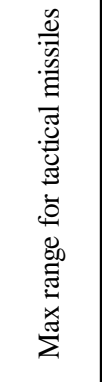 & 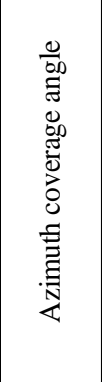 & 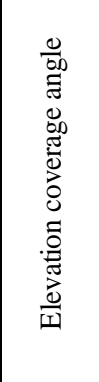 & 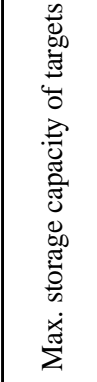 & 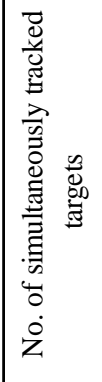 & 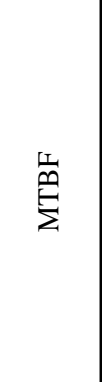 & 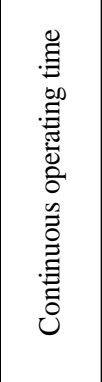 & 总 & 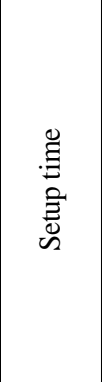 & 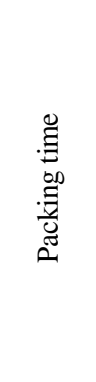 \\
\hline SLC-2 & 0.0382 & 0.0545 & 0.0625 & 0.0733 & 0.0442 & 0.0589 & 0.0206 & 0.0232 & 0.0182 & 0.0275 & 0.0087 & 0.0101 & 0.0120 \\
\hline Radar Complex & 0.0636 & 0.0545 & 0.0625 & 0.1067 & 0.0295 & 0.0198 & 0.0132 & 0.0348 & 0.0267 & 0.0275 & 0.0087 & 0.0072 & 0.0052 \\
\hline RA2 radar & 0.0763 & 0.0908 & 0.1249 & 0.1067 & 0.0442 & 0.0589 & 0.0206 & 0.0232 & 0.0243 & 0.0165 & 0.0116 & 0.0072 & 0.0052 \\
\hline WLR radar & 0.0509 & 0.0545 & 0.0468 & 0.0533 & 0.0442 & 0.0496 & 0.0186 & 0.0203 & 0.0219 & 0.0248 & 0.0087 & 0.0072 & 0.0052 \\
\hline
\end{tabular}

Now, applying equations (9) and (10) or using the SANNA software[26], the ideal and the anti-ideal solutions are respectively computed as given in table 8. 
Military Technical College

Kobry Elkobbah,

Cairo, Egypt

April 19-21,2016

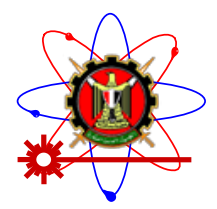

$8^{\text {th }}$ International Conference on Mathematics and Engineering Physics (ICMEP-8)

Table 8. Ideal and negative ideal solutions

\begin{tabular}{|c|c|c|c|c|c|c|c|c|c|c|c|c|c|}
\hline & \multicolumn{13}{|c|}{ CRITERIA } \\
\hline & 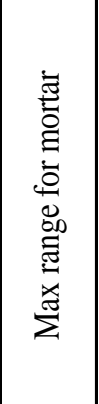 & 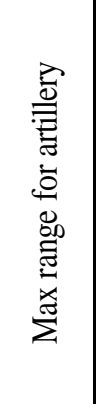 & 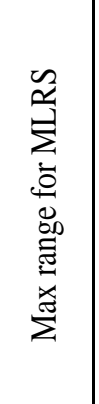 & 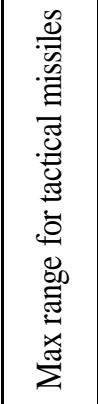 & 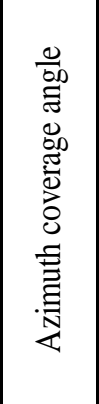 & 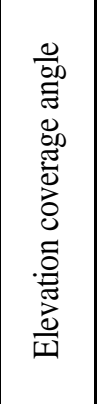 & 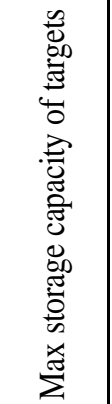 & 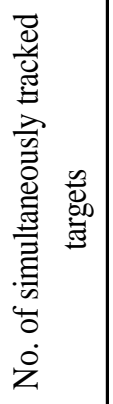 & 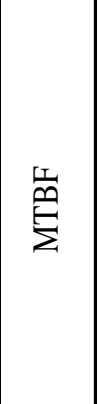 & 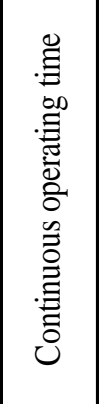 & 总 & 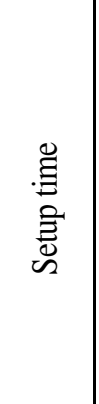 & 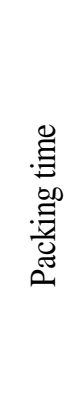 \\
\hline$V^{+}$ & 0.076 & 0.091 & 0.125 & 0.107 & 0.044 & 0.059 & 0.021 & 0.035 & 0.027 & 0.028 & 0.009 & 0.007 & 0.005 \\
\hline$V^{-}$ & 0.038 & 0.054 & 0.047 & 0.053 & 0.029 & 0.020 & 0.013 & 0.020 & 0.018 & 0.017 & 0.012 & 0.010 & 0.012 \\
\hline
\end{tabular}

Then applying equations (11) and (12) or using SANNA software, the separation measures of each alternative radars from the ideal and the anti-ideal solutions are estimated, as shown in table 9 .

Table 9. Separation measures

\begin{tabular}{|c|c|c|c|c||}
\hline \hline Radar & SLC-2 & Radar Complex & RA2 radar & WLR radar \\
\hline$S_{i}^{+}$ & 0.0903 & 0.0848 & 0.0196 & 0.1060 \\
\hline$S_{i}^{-}$ & 0.0519 & 0.0665 & 0.01171 & 0.0407 \\
\hline
\end{tabular}

Finally, the relative closeness values of all the alternative radars with respect to the ideal solution are computed by applying equation (13) or using SANNA software, as given in table 10. This results in a ranking of radars as 3-2-1- 4 and reveals that RA2 radar is our best choice.

Table 10. Relative closeness values

\begin{tabular}{|c|c|c|c|c||}
\hline \hline$\underline{\text { Radar }}$ & $\underline{\text { SLC-2 }}$ & $\underline{\text { Radar Complex }}$ & $\underline{\text { RA2 radar }}$ & $\underline{\text { WLR radar }}$ \\
\hline$\underline{C_{i}}$ & $\underline{0.3650}$ & $\underline{0.4396}$ & $\underline{0.8570}$ & $\underline{0.2774}$ \\
\hline
\end{tabular}

\section{Selection Using ELECTRE I}

For solving our problem using ELECTRE I method, we will use “ELECTRE IS" [27]. ELECTRE ISis a decision making tool designed to solve MCDM problems using ELECTRE I method. It was originated by the laboratory for analysis and modelling of decision support systems, Dauphine University in France.

The concordance matrix is: 
Military Technical College

Kobry Elkobbah,

Cairo, Egypt

April 19-21,2016

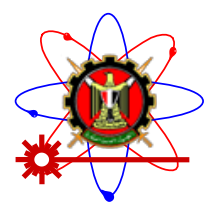

$8^{\text {th }}$ International Conference on Mathematics and Engineering Physics (ICMEP-8)

The discordance matrix is:

$$
C=\left[\begin{array}{cccc}
0 & 0.58 & 0.34 & 0.81 \\
0.78 & 0 & 0.37 & 0.78 \\
0.93 & 0.83 & 0 & 0.93 \\
0.43 & 0.40 & 0.18 & 0
\end{array}\right]
$$

$$
D=\left[\begin{array}{cccc}
0 & 1.0 & 1.0 & 1.0 \\
0.9 & 0 & 1.0 & 1.0 \\
0.16 & 0.32 & 0 & 0.12 \\
0.5 & 0.83 & 1.0 & 0
\end{array}\right]
$$

Using the threshold values $\bar{c}=0.5678$ and $\bar{d}=0.7358$ provided by the decision maker, the aggregate matrix (matrix of outranking) will be as follows:

and the final graph of outranking is:

$$
E=\left[\begin{array}{llll}
0 & 0 & 0 & 1 \\
1 & 0 & 0 & 1 \\
1 & 1 & 0 & 1 \\
0 & 0 & 0 & 0
\end{array}\right]
$$

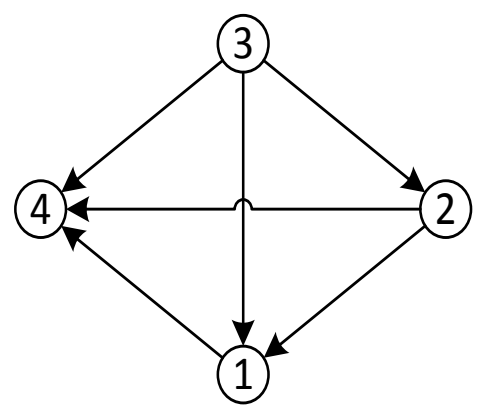

Figure 1. Final outranking graph

This means that RA2 radar dominates the other three alternatives and the final ranking is 3-2-1-4.

\section{Selection Using VIKOR}

For solving this problem using VIKOR method, at first, the best and the worst values of all the criteria are identified. Now, the values of $\mathrm{Ei}$ and $\mathrm{Fi}$ are calculated using equation (18) or (20) and (19) respectively, as given in table 11. Table 11 also shows the Pi values(for $v=$ 0.5). Arranging these values in ascending order, the best choice of alternatives is RA2 radar and the relative ranking of radarsis3-2-1-4.

Table 11. Ei, Fi and Pi values

$$
\text { Radar }
$$

Ei

$\mathrm{Fi}$

$\mathrm{Pi}$ 
Military Technical College

Kobry Elkobbah,

Cairo, Egypt

April 19-21,2016

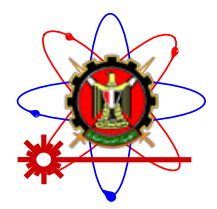

$8^{\text {th }}$ International Conference on Mathematics and Engineering Physics (ICMEP-8)

\begin{tabular}{cccc}
\hline \hline SLC-2 & 0.606 & 0.131 & 0.764 \\
\hline Radar Complex & 0.516 & 0.131 & 0.682 \\
\hline RA2 radar & 0.123 & 0.049 & 0.000 \\
\hline WLR radar & 0.670 & 0.176 & 1.000 \\
\hline \hline
\end{tabular}

\section{Comparative Analysis}

To measure the agreement between the ranks obtained by the sixoutranking methods used in solving this weapon locating and fire correction radar selection problem, their relative ranking performance are compared using the following measures:

(a) Spearman's rank correlation coefficient,and

(b) Agreement between the top three ranked alternatives.

\section{Spearman's rank correlation coefficient}

Spearman's rank correlation coefficient denoted by $\rho$ was first introduced by Spearman [28], and it is used to determine the measure of association between ranks obtained by different MCDM methods. The sign of the correlation coefficient (i.e., positive or negative) defines the direction of the relationship and the absolute value indicates the strength of the correlation. It can be calculated by:

$$
\rho=1-\frac{6 \sum d_{i}^{2}}{n\left(n^{2}-1\right)}
$$

where

n number of sample size (no. of alternative radars)

di difference between ranks

Table 12 shows the Spearman's rank correlation coefficient values when the rankings of the radar alternatives are compared in pairwise. The results are obtained by using SPSS version 20.0 (a software package used for statistical analysis) [29].

Table 12. Spearman rank correlation coefficient values

\begin{tabular}{||c|c|c|c|c|c|c||}
\hline & SAW & WPM & AHP & TOPSIS & ELECTRE I & VIKOR \\
\hline SAW & - & 1.0 & -0.4 & 1.0 & 1.0 & 1.0 \\
\hline WPM & & - & -0.4 & 1.0 & 1.0 & 1.0 \\
\hline AHP & & & - & -0.4 & -0.4 & -0.4 \\
\hline TOPSIS & & & & - & 1.0 & 1.0 \\
\hline ELECTRE I & & & & & - & 1.0 \\
\hline
\end{tabular}

We notice that a perfect match exists between all the methods except AHP.

\section{The Agreement between the Top three Ranked Alternatives}

As the decision maker may be sometimes interested to select the best radar as the single choice, another test is performed based on the agreement between the top three ranked alternatives. Here, a result of $(1,2,3)$ means the first, second and third ranks match; (1, 2, \#) 
Military Technical College

Kobry Elkobbah,

Cairo, Egypt

April 19-21,2016

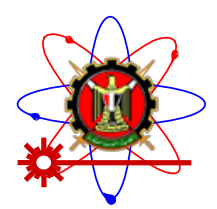

$8^{\text {th }}$ International Conference on

Mathematics and Engineering

Physics (ICMEP-8)

means the first and second ranks match; (1, \#, \#) means only the first ranks match; and (\#, \#, \#) means no match. It is apparent from table 13, that AHP method result in the maximum number of mismatches with respect to the ranking of the top three alternative radars..

Table 13. The agreement between the top three ranked alternatives

\begin{tabular}{||c|c|c|c|c|c|c||}
\hline \hline & SAW & WPM & AHP & TOPSIS & ELECTRE I & VIKOR \\
\hline SAW & - & $(1,2,3)$ & $(\#, 2, \#)$ & $(1,2,3)$ & $(1,2,3)$ & $(1,2,3)$ \\
\hline WPM & & - & $(\#, 2, \#)$ & $(1,2,3)$ & $(1,2,3)$ & $(1,2,3)$ \\
\hline AHP & & & - & $(\#, 2, \#)$ & $(\#, 2, \#)$ & $(\#, 2, \#)$ \\
\hline TOPSIS & & & & - & $(1,2,3)$ & $(1,2,3)$ \\
\hline ELECTRE I & & & & & - & $(1,2,3)$ \\
\hline
\end{tabular}

Conclusion

A key strength of the present study was the ability to solve the problem of selecting a weapon locating and fire correction radar on scientific basis. The results of the study have shown that RA2 radar was selected as the primarily radar with five methods out of six. Only AHP did not agree to this choice and so I do not recommend it to be used for this kind of selection problems. The analysis performed on the results has shown high degree of agreement between the different ranks obtained by the different used methods. Consequently, for a given selection problem, more attention is to be paid on the proper selection of the relevant criteria and alternatives, not on choosing the most appropriate outranking method to be adopted. The results have revealed the possibility of using MCDM methods for solving the problems of selecting weapon and military equipment.

\section{References}

[1] J. Muller, A Treatise of Artillery ...: To which is Prefixed, an Introduction, with a Theory of Powder Applied to Fire-arms. John Millan, 1768.

[2] J. Fülöp, “Introduction to decision making methods,” 2005.

[3] K. MacCrimmon, "Decision making among multiple-attribute alternatives: a survey and consolidated approach,” 1968.

[4] M. Janic and A. Reggiani, "An application of the multiple criteria decision making (MCDM) analysis to the selection of a new hub airport," Eur. J. Transp. Infrastruct. Res., vol. 2, no. 2, pp. 113-141, 2002.

[5] V. Athawale and S. Chakraborty, "Material selection using multi-criteria decisionmaking methods: a comparative study," Proc. Inst. Mech. Eng. Part L J. Mater. Des. Appl., vol. 226, no. 4, pp. 266-285, 2012. 
Military Technical College

Kobry Elkobbah,

Cairo, Egypt

April 19-21,2016

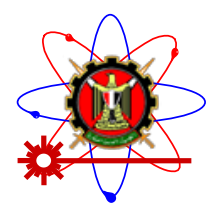

$8^{\text {th }}$ International Conference on Mathematics and Engineering Physics (ICMEP-8)

[6] G. Wang, L. Qin, G. Li, and L. Chen, "Landfill site selection using spatial information technologies and AHP: a case study in Beijing, China.,” J. Environ. Manage., vol. 90, no. 8, pp. 2414-2421, 2009.

[7] M. Hajeeh and A. Al-Othman, "Application of the analytical hierarchy process in the selection of desalination plants,” Desalination, vol. 174, no. 1, pp. 97-108, 2005.

[8] L. A. Fernandes, J.M.; Prozil Rodrigues, S.; Costa, "Comparing AHP and ELECTRE I for prioritizing software requirements,” Softw. Eng. Artif. Intell. Netw.

Parallel/Distributed Comput. (SNPD), 2015 16th IEEE/ACIS Int. Conf. IEEE, pp. 1-8, 2015.

[9] V. Agrawal, V. Kohli, and S. Gupta, "Computer aided robot selection: the "multiple attribute decision making’approach,” Int. J. Prod. Res., vol. 29, no. 8, pp. 1629-1644, 1991.

[10] N. Fajar, "Decision Support System for Evaluation Procurement of Goods with Simple Additive Weighting Method (SAW)," in International Conference on Information Systems for Business Competitiveness, 2013, pp. 211-215.

[11] K. Gaurh, I. Khan, and M. Ghosh, "MCDM Techniques for the Selection of Material Handling Equipment in the Automobile Industry,” Int. J. Mod. Eng. Res., vol. 4, no. 11, pp. 46-52, 2014.

[12] K. Goztepe and C.Kahraman, “A New Approach to Military Decision Making Process: Suggestions from MCDM Point of View," in International Conference on Military and Security Studies (ICMSS), 2015, pp. 118-122.

[13] R. Mohanty, "Project selection by a multiple-criteria decision-making method: an example from a developing country,” Int. J. Proj. Manag., vol. 10, no. 1, pp. 31-38, 1992.

[14] A. Jahan, F. Mustapha, M. Y. Ismail, S. M. Sapuan, and M. Bahraminasab, “A comprehensive VIKOR method for material selection,” Mater. Des., vol. 32, no. 3, pp. 1215-1221, 2011.

[15] J. R. San Cristóbal, "Multi-criteria decision-making in the selection of a renewable energy project in spain: The Vikor method,” Renew. Energy, vol. 36, no. 2, pp. 498502, 2011.

[16] A. Civic and B. Vucijak, "Multi-criteria Optimization of Insulation Options for Warmth of Buildings to Increase Energy Efficiency,” Procedia Eng., vol. 69, pp. 911-920, 2014. 
Military Technical College

Kobry Elkobbah,

Cairo, Egypt

April 19-21,2016

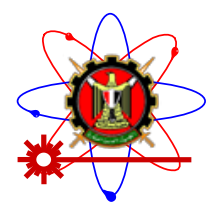

$8^{\text {th }}$ International Conference on Mathematics and Engineering Physics (ICMEP-8)

[17] U. Ahmadi, A., Gupta, S., Karim, R., \& Kumar, "Selection of maintenance strategy for aircraft systems using multi-criteria decision making methodologies,” Int. J. Reliab. Qual. Saf. Eng., vol. 17, no. 3, pp. 223-243, 2010.

[18] T. L. Saaty, The Analytic Hierarchy Process: Planning, Priority Setting, Resource Allocation. RWS, 1990.

[19] G.-H. Tzeng and J.-J. Huang, Multiple Attribute Decision Making: Methods and Applications. CRC Press, 2011.

[20] T. Saaty, “The Analytic (Hierarchy) Process, New York, St,” Louis ua, 1980.

[21] V. M. Athawale and S. Chakraborty, "A comparative study on the ranking performance of some multi-criteria decision-making methods for industrial robot selection,” Int. $J$. Ind. Eng. Comput., vol. 2, no. 4, pp. 831-850, Oct. 2011.

[22] B. Roy and P. Vincke, "Multicriteria analysis: survey and new directions,” Eur. J. Oper. Res., vol. 8, no. 3, pp. 207-218, 1981.

[23] S. Opricovic and G.-H. Tzeng, "Compromise solution by MCDM methods: A comparative analysis of VIKOR and TOPSIS,” Eur. J. Oper. Res., vol. 156, no. 2, pp. 445-455, Jul. 2004.

[24] S. Opricovic and G.-H. Tzeng, "Extended VIKOR method in comparison with outranking methods,” Eur. J. Oper. Res., vol. 178, no. 2, pp. 514-529, Apr. 2007.

[25] T. L. Saaty, "Scaling methods for priorities in hierarchical structures," J. Math. Psychol., vol. 15, no. 3, pp. 234-281, 1977.

[26] P. U. Josef Jablonský, "MS Excel based system for multicriteria evaluation of alternatives,” Univ. Econ. Prague, 1998.

[27] "Laboratory for Analysis and Modelling of Decision Support Systems (LAMSADE (UMR 7243), Paris Dauphine University, Available: http://www.lamsade.dauphine.fr/spip.php?article558.” .

[28] C. Spearman, "The proof and measurement of association between two things," Am. J. Psychol., vol. 15, no. 1, pp. 72-101, 1904.

[29] IBM, “IBM SPSS Statistics 23 Documentation - United States Available: http://www01.ibm.com/software/analytics/spss/index.html.” IBM, 2015. 